\title{
AN EXPERIMENTAL MODEL TO DESCRIBE THE TEMPERATURE VARIATION OF THE DISK DURING BRAKING TESTS
}

\author{
P. D. Neis ${ }^{1,2}$, G. L. P. G. Zanetti ${ }^{1}$, Y. Perez Delgado ${ }^{2}$, P. De Baets ${ }^{2,}$ and N. F. Ferreira ${ }^{1}$ \\ ${ }^{1}$ Federal University of Rio Grande do Sul, Brazil \\ ${ }^{2}$ Ghent University, Laboratory Soete, Belgium
}

\begin{abstract}
In the present paper an experimental model is created to describe the temperature variation of the disk inexperiments performed on a laboratory-scale tribometer. A commercially available brake pad and disk are used in the tests. The operating parameters seton the tribometer are a constant rotation of $660 \mathrm{rpm}$, torque of $10 \mathrm{Nm}$ and $15 \mathrm{Nm}$, braking time of $25 \mathrm{~s}$ and $50 \mathrm{~s}$ and initial temperature of $50^{\circ} \mathrm{C}$ and $100^{\circ} \mathrm{C}$. The evaluation of the thermal results is done by using a statistical model for analysis of variance (Anova). In order to obtain a mathematical equation to describe the temperature variation of the disk, a linear regression model is used. At the same time, the effect from both, temperature variation and initial temperature, on the coefficient of friction are investigated.The effect of the temperature variation on coefficient of friction is complex and it seems to not have correlation between them both. When the initial temperature is changed from $50^{\circ} \mathrm{C}$ to $100^{\circ} \mathrm{C}$ the coefficient of friction is increased. The results from the current paper shows that the experimental model can be used to predict the temperature variation of the disk during braking tests performed on the tribometer.
\end{abstract}

Keywords Experimental model, tribometer, operating parameters, temperature variation.

\section{INTRODUCTION}

Tribometers have been used for surveys about friction materials, in order to a better comprehension about tribological phenomena. These machines have reduce cost in relation to other equipments, such as inertial dynamometers, and the tests produce a lot of great important data to the development of new automotive brake pads. In the theory of scale proposed by [1], the density of energy dissipated in the pads, sliding velocity, deceleration and braking stop time should be equivalent in both full and scale machines. Therefore, one of the operating parameters setting in this paper is the constant torque, which represents the energy transmitted to the system.

This paper aims to determinate an experimental model for the temperature variation in a laboratory-scale tribometer. The input data are braking time, initial temperature and braking torque. The increase in the temperature generates more wear in the pad, which is one of the main focus of tribology [2]. This empirical model will be important to predict the temperature of the disk during braking and also to be part of a methodology to the tests perfomed on the laboratory-scale tribometer.

\section{TRIBOLOGY}

The word tribology derives from the greek, where tribo means rubbing and the suffix "logy" means study. Tribology was used, officially, for the first time in 1966 by the Jost report, which was presented in the committee of the british department of education and science. In this report the word was defined as "the science and technology of interacting surfaces in relative motion and of related subjects and practices" [10]. Jost was the first author to study the economic impact due to the use of the tribology knowledge. This study is considered a mark field of tribology [4]. Through the use of this knowledge is possible to reduce about $20 \%$ of the loss due to wear. The environmental issue is also important [3]. Furthermore, a study conducted by [5], which uses data obtained in a medium size passenger car during an urban cycle showed that only $12 \%$ of the fuel are transformed in mechanical energy to the driving wheels, and around $15 \%$ are losses, primarily by tribological contact.

Perhaps the oldest evidence of tribology occurred in the paleolithic period [6], with the discovery of fire by the man from the heat generate by friction between pieces of wood or from sparks resulting from the clash between the stones. The egyptians used sleds to transport a large and heavy statue, according illustrates the Figure 1. In this situation, 172 slaves worked to drag the statue, whose weigh was approximately 
$600 \mathrm{kN}$. On the foot of the statue can be seen a man pouring some liquid in the path in order to reduce the friction and make the transport easy.

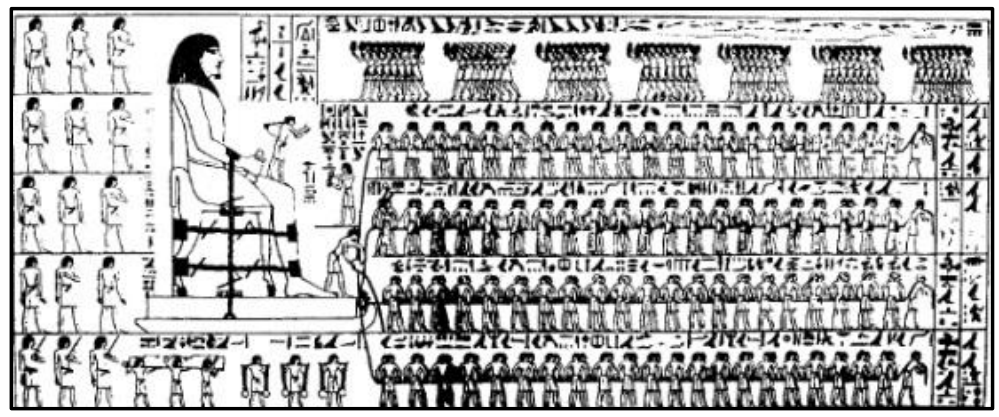

Figure1. Transport of an egyptian statue with the help of tribological knowledge.

\section{TRIBOMETER}

The tribometer is a machine used to measure the coefficient of friction between two or more surfaces in relative motion. This equipment is a important tool for researches that intend a better understanding about tribology phenomena, including studies about friction materials for automotive brake pads, as showed by recent reviews in the literature [7-8]. The laboratory-scale tribometer used to perform the tests has been developed by the Laboratory of Tribology (LATRIB) located at UFRGS.

The coefficient of friction is evaluated by dividing the braking torque by the normal force on the disk surface multiplied by sliding radius. Equation 1 shows the mentioned relationship:

$$
\mu=\frac{M}{R_{e} \cdot F_{N}}
$$

where $\mu$ represents the coefficient of friction, $M$ the braking torque $[\mathrm{Nm}], R_{e}$ the sliding radius $[\mathrm{m}]$ e $F_{N}$ the normal force $[\mathrm{N}]$.

The normal force is measured by means of a load cell while the braking torque is obtained by a torque transducer, which is directly assembled on the shaft of the machine. The measurement system of the disk temperature is composed by a thermocouple embedded in the disk at $6 \mathrm{~mm}$ from the surface. The output signal of this sensor is transmitted by using a slip ring. Figure 2 illustrates the scheme of the tribometer and Figure 3 an actual picture. More information about this machine can be found in another publication [9].

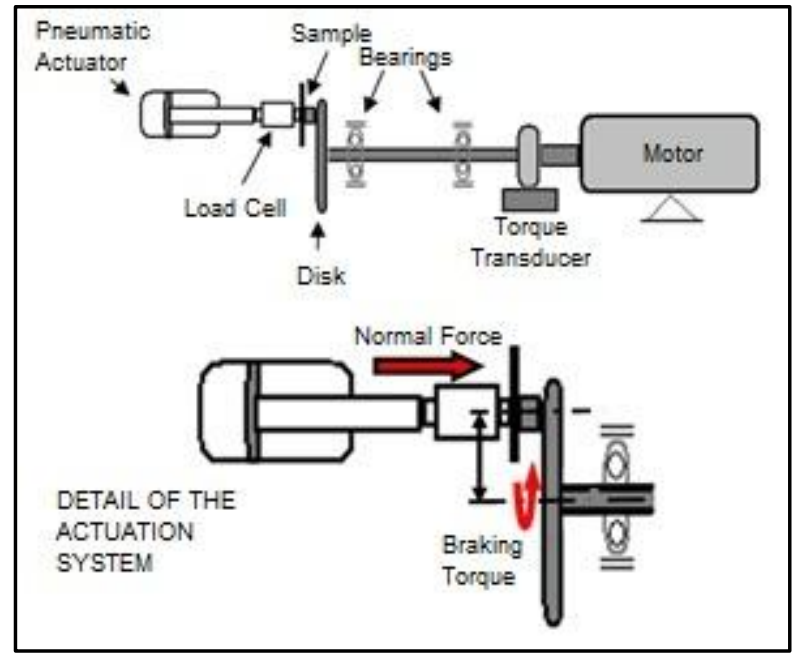

Figura 2. Scheme of the laboratory-scale tribometer. 


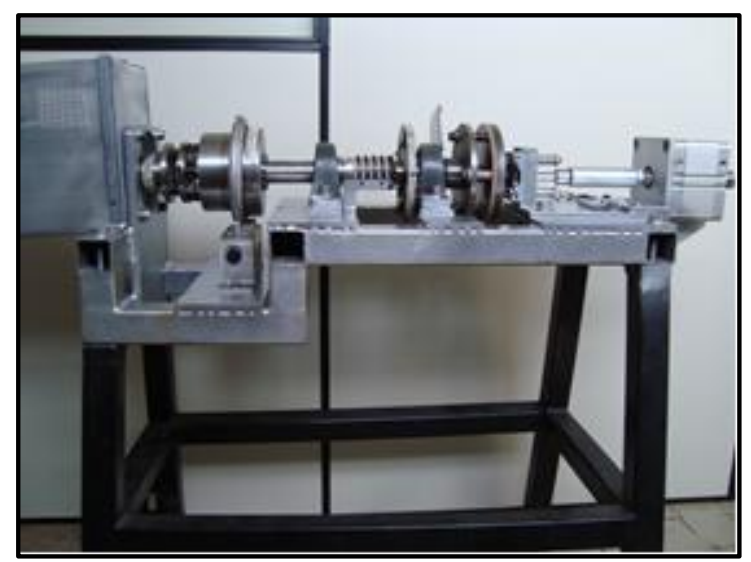

Figura 3. Picture of the actual laboratory-scale tribometer.

\section{EXPERIMENTS}

The project of the experiments is based on the idea of NBR 14794, in which the tests are performed under constant speed of $660 \mathrm{rpm}$ and constant torque. Input data have 2 levels which are represented in the Table 1. Each test condition has been repeated 3 times in order to minimize the random error.

Table 1. Input data.

\begin{tabular}{|c|c|c|}
\hline Operating Parameters & \multicolumn{2}{|c|}{ Levels } \\
\hline Braking Time (s) & 25 & 50 \\
\hline Initial Temperature $\left({ }^{\circ} \mathbf{C}\right)$ & 50 & 100 \\
\hline Torque $(\mathrm{Nm})$ & 10 & 15 \\
\hline
\end{tabular}

Regards to the output data, an average of the disk temperature in the last second (final temperature) has been made for each test. After that, the difference between the final and initial temperature of the disk was determined so as to obtain the temperature variation.

The significance evaluation of the input factors in relation to temperature variation is performed by using an analysis of variance (ANOVA). The experimental model for the temperature variation is obtained through a linear regression. All statistic calculus has been done in Microsoft Excel 2010.

\section{RESULTS}

Results experimentally obtained for the temperature variation in the tribometer disk are shown in the Table 2. Alphanumeric characters "A", "B" e "C" are used to represent, respectively, braking time, initial temperature and torque.

Table 2. Experimental temperature variation.

\begin{tabular}{|c|c|c|c|c|}
\cline { 2 - 5 } \multicolumn{1}{c|}{} & \multicolumn{2}{c|}{$\mathbf{5 0}^{\circ} \mathbf{C}$} & \multicolumn{2}{c|}{$100{ }^{\circ} \mathbf{C}$} \\
\cline { 2 - 5 } \multicolumn{1}{c|}{$25 s$} & $\mathbf{1 0} \mathbf{~ N m}$ & $\mathbf{1 5 N m}$ & $\mathbf{1 0} \mathbf{~ N m}$ & $\mathbf{1 5 N m}$ \\
\hline \multirow{4}{*}{$50 s$} & 23,774 & 41,862 & 16,430 & 32,344 \\
\cline { 2 - 5 } & 24,629 & 38,506 & 20,246 & 33,357 \\
\cline { 2 - 5 } & 22,240 & 43,695 & 16,533 & 32,264 \\
\hline \multirow{3}{*}{$\mathbf{s}$} & 45,832 & 85,064 & 34,623 & 59,434 \\
\cline { 2 - 5 } & 43,640 & 83,307 & 33,306 & 61,954 \\
\cline { 2 - 5 } & 44,299 & 84,082 & 35,128 & 62,642 \\
\hline
\end{tabular}


Table 3 presents the results of the analysis of variance (ANOVA) for the input parameters A, B e C isolated and matched to each other. A Confidence Index $(\mathrm{Cl})$ of $95 \%$ is used in these results and the calculus method is based on [11].

Table 3. Analysis of Variance (ANOVA).

\begin{tabular}{|c|c|c|c|c|c|c|}
\hline $\begin{array}{c}\text { Input } \\
\text { Parameters }\end{array}$ & Sum of Squares & ${ }^{1}$ DOF & $\begin{array}{c}\text { Average } \\
\text { Square }\end{array}$ & F calculated & $\begin{array}{c}\text { F tabulated } \\
\text { (Cl=95\%) }\end{array}$ & $\begin{array}{c}\text { S - Significant } \\
\text { NS - Not } \\
\text { Significant }\end{array}$ \\
\hline A & 4467,17 & 1,00 & 4467,17 & 1855,17 & 4,49 & $\mathrm{~S}$ \\
\hline B & 848,12 & 1,00 & 848,12 & 352,22 & 4,49 & $\mathrm{~S}$ \\
\hline C & 3695,93 & 1,00 & 3695,93 & 1534,88 & 4,49 & $\mathrm{~S}$ \\
\hline AB & 128,85 & 1,00 & 128,85 & 53,51 & 4,49 & $\mathrm{~S}$ \\
\hline AC & 429,07 & 1,00 & 429,07 & 178,19 & 4,49 & $\mathrm{~S}$ \\
\hline BC & 89,61 & 1,00 & 89,61 & 37,21 & 4,49 & $\mathrm{~S}$ \\
\hline ABC & 35,15 & 1,00 & 35,15 & 14,60 & 4,49 & $\mathrm{~S}$ \\
\hline Erro & 38,53 & 16,00 & 2,41 & & & \\
\hline Total & 9732,43 & 23,00 & 423,15 & & & \\
\hline
\end{tabular}

DOF represents the degrees of freedom of each parameter.

It is observed that all analyzed conditions are significant, because $\mathrm{F}$ calculated is bigger than $\mathrm{F}$ tabulated. It shows that all input factors should be taken into account in the moment of the experimental modeling of the temperature variation. However, the 3 input data used in this paper do not have a linear isolated ratio with the output variable, according to the first regression model. So, a second regression model has been run without the linear parameters, which adds square factors as shows Table 4.

Table 4. Second regression model.

\begin{tabular}{|c|c|c|c|c|}
\cline { 2 - 5 } \multicolumn{1}{c|}{} & Coefficients & Standard Error & P value & $\begin{array}{c}\text { S - Significant } \\
\text { NS - Not } \\
\text { Significant }\end{array}$ \\
\hline Intersection & $-22,43467$ & 5,41677 & 0,00077 & S \\
\hline AB & 0,01195 & 0,00517 & 0,03441 & S \\
\hline AC & 0,25149 & 0,03205 & 0,00000 & S \\
\hline BC & 0,02718 & 0,01603 & 0,10930 & NS \\
\hline ABC & $-0,00155$ & 0,00041 & 0,00150 & S \\
\hline A $^{2}$ & $-0,01995$ & 0,00545 & 0,00211 & S \\
\hline B $^{2}$ & $-0,00200$ & 0,00136 & 0,16209 & NS \\
\hline $\mathbf{C}^{2}$ & $-0,08593$ & 0,05068 & 0,10932 & NS \\
\hline
\end{tabular}

The regression routine was performed a third time in order to find a better correlation between the theoretical and experimental results. In this case, only the significant factors $(P$ value $<0,05$, for a $\mathrm{Cl}$ of 95\%) were considered. Table 5 shows the values of the final regression model, in addition to the experimental and theoretical results of temperature variation. 
Table 5. Comparison between experimental results and theoretical data, obtained via regression model.

\begin{tabular}{|c|c|c|c|c|c|c|}
\hline $\mathbf{A B}$ & $\mathbf{A C}$ & $\mathbf{A B C}$ & $\mathbf{A}^{\mathbf{2}}$ & $\begin{array}{c}\Delta \mathbf{T} \\
\left({ }^{\circ} \mathbf{C}\right)\end{array}$ & $\begin{array}{c}\text { Theoretical } \\
\mathbf{\Delta} \mathbf{T}\left({ }^{\circ} \mathbf{C}\right)\end{array}$ & Error \\
\hline 1250 & 250 & 12500 & 625 & 23,774 & 23,161 & 0,613 \\
\hline 1250 & 250 & 12500 & 625 & 24,629 & 23,161 & 1,469 \\
\hline 1250 & 250 & 12500 & 625 & 22,240 & 23,161 & $-0,921$ \\
\hline 1250 & 375 & 18750 & 625 & 41,862 & 42,546 & $-0,685$ \\
\hline 1250 & 375 & 18750 & 625 & 38,506 & 42,546 & $-4,041$ \\
\hline 1250 & 375 & 18750 & 625 & 43,695 & 42,546 & 1,149 \\
\hline 2500 & 250 & 25000 & 625 & 16,430 & 17,903 & $-1,473$ \\
\hline 2500 & 250 & 25000 & 625 & 20,246 & 17,903 & 2,342 \\
\hline 2500 & 250 & 25000 & 625 & 16,533 & 17,903 & $-1,370$ \\
\hline 2500 & 375 & 37500 & 625 & 32,344 & 31,683 & 0,661 \\
\hline 2500 & 375 & 37500 & 625 & 33,357 & 31,683 & 1,674 \\
\hline 2500 & 375 & 37500 & 625 & 32,264 & 31,683 & 0,581 \\
\hline 2500 & 500 & 25000 & 2500 & 45,832 & 44,784 & 1,048 \\
\hline 2500 & 500 & 25000 & 2500 & 43,640 & 44,784 & $-1,144$ \\
\hline 2500 & 500 & 25000 & 2500 & 44,299 & 44,784 & $-0,485$ \\
\hline 2500 & 750 & 37500 & 2500 & 85,064 & 83,555 & 1,509 \\
\hline 2500 & 750 & 37500 & 2500 & 83,307 & 83,555 & $-0,248$ \\
\hline 2500 & 750 & 37500 & 2500 & 84,082 & 83,555 & 0,527 \\
\hline 5000 & 500 & 50000 & 2500 & 34,623 & 34,269 & 0,354 \\
\hline 5000 & 500 & 50000 & 2500 & 33,306 & 34,269 & $-0,963$ \\
\hline 5000 & 500 & 50000 & 2500 & 35,128 & 34,269 & 0,859 \\
\hline 5000 & 750 & 75000 & 2500 & 59,434 & 61,829 & $-2,395$ \\
\hline 5000 & 750 & 75000 & 2500 & 61,954 & 61,829 & 0,125 \\
\hline 5000 & 750 & 75000 & 2500 & 62,642 & 61,829 & 0,813 \\
\hline
\end{tabular}

Equation 2 represents the mathematical formulation generated by the regression routine:

$\Delta T=-13,8637+0,0048 A B+0,19998 A C-0,0009 A B C-0,0123 A^{2}$

where $\Delta T$ is the temperature variation of the disk, $\mathrm{A}$ the braking time, $\mathrm{B}$ the initial temperature and $\mathrm{C}$ the torque.

The coefficient of determination $\left(R^{2}\right)$ obtained is 0,995 , which means that the equation obtained provides $99.5 \%$ correlation between the input and output variables. Figure 4 illustrates the relation between the experimental and theoretical results.

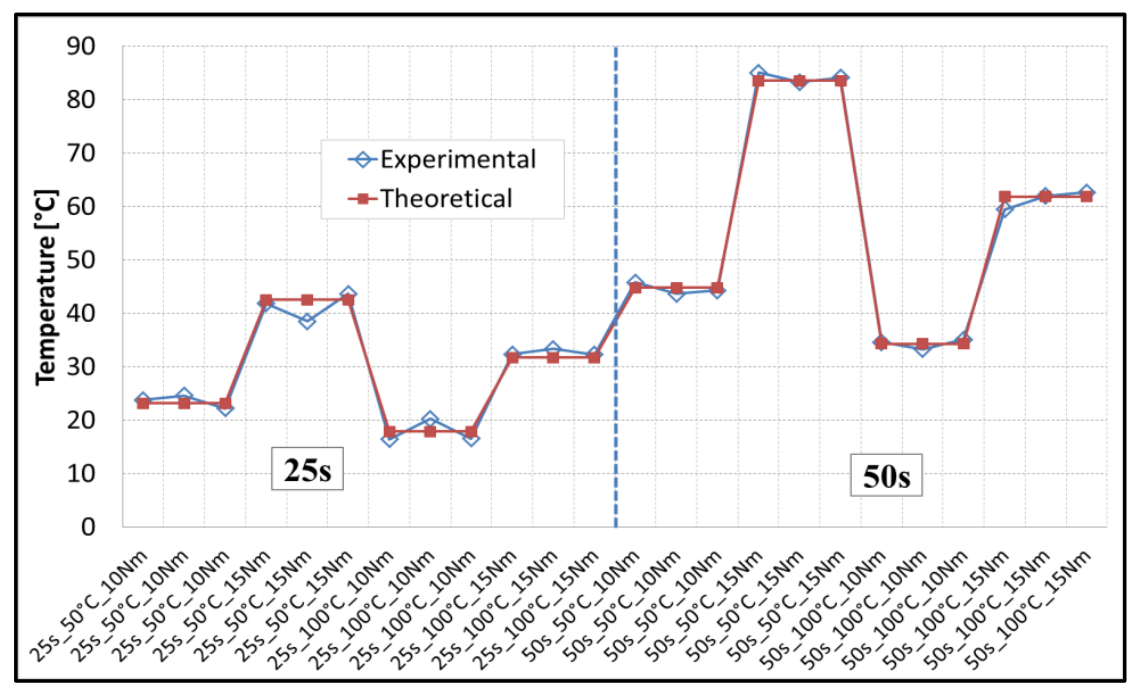

Figure 4. Comparison between experimental and theoretical curves. 
In order to evaluate the effect of the temperature variation in the coefficient of friction, it was used experimental data from the test executed with the braking time of $25 \mathrm{~s}$. Figure 5 shows the average curve of the coefficient of friction calculated for the 3 repetitions of each condition.

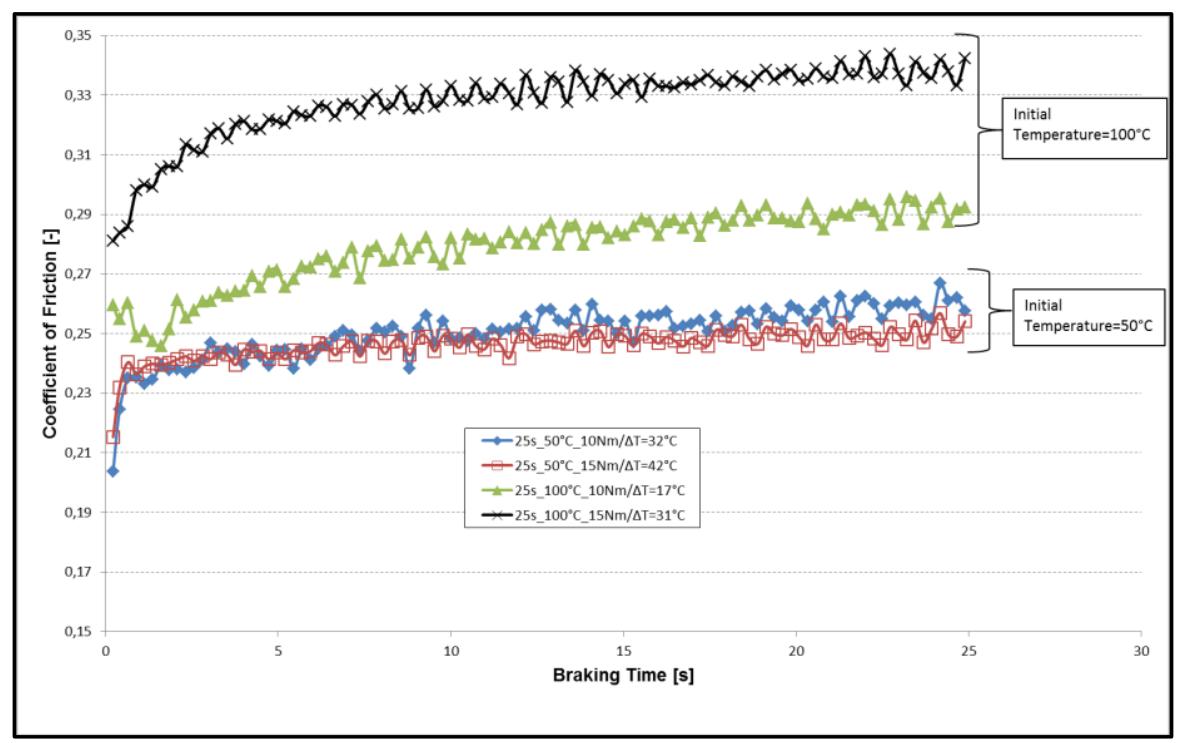

Figure 5. Curves of coefficient of friction for different initial temperature and torque.

It is verified that the ratio analysis between temperature variation and coefficient of friction is complex, because when the temperature is modified, one of the variables (torque or initial temperature) also changes. Nevertheless, it is seen that initial temperature and coefficient of friction are associated. Results in the Figure 5 show that increasing the initial temperature, the coefficient of friction also increases.

\section{CONCLUSIONS}

For the range of conditions evaluated, the experimental model presented in the current paper is able to reproduce the temperature variation of the disk during braking tests performed on the laboratory-scale tribometer. Mathematical equation generated by the linear regression model, whose correlation between input and output data is $99,5 \%\left(R^{2}=0,995\right)$, can be used to assess the disk temperature from the braking time, initial temperature and torque. Thus, this equation becomes an important support tool for the designed tribometer.

However, it is not possible to establish correlation between temperature variation of the disk and the friction coefficient, since two parameters change simultaneously. But it can concluded that the coefficient of friction increases when the initial temperature level of the disk change from $50^{\circ} \mathrm{C}$ to $100^{\circ} \mathrm{C}$.

\section{REFERENCES}

[1] J. Wilson, W. G. Belford, G. T. Bowsher, Testing Machines For Scale Vehicle Brake Installations, The Engineer, 317-323, 1968.

[2] K. Kato, K. Adach, Modern Tribology Handbook, Wear Mechanisms, Ed. CRC Press LLC Vol.2., 2001.

[3] H. P. Jost, Tribology-Origin And Future, Wear v.136, pp.1-17, 1990.

[4] A. Sinatora, Tribologia: Um Resgate Histórico E O Estado Da Arte, Prova de Erudição, São Paulo, 2005.

[5] B. S. Andersson, Company perspectives in vehicle tribology - Volvo. In: 17th Leeds-Lyon Symposium on Tribology-Vehicle Tribology, Tribology Series, 18. Oxford, UK: Elsevier Ltd, p. 503-6, 1991.

[6] D. Dowson, History of Tribology, published by Longman Group Limited, Londres, Inglaterra, 1979.

[7] Y. Desplanques, O. Roussette, G. Degallaix, M. Francois, A-L. Bulthé, L. Sabatier, A Reduced-Scale Test For Pad-Disc Contact Tribological Analysis In Railway Braking, Wear 262, 2006.

[8] Y. Desplanques, G. Degallaix, R. Copin, Y. Berthier, A Tribometer For The Study Of Materials Under Railway Braking Conditions, Tribology and Interface Engineering Series, Vol. 39, pg. 381-391, 2001. 
[9] P. D. Neis, Projeto e Construção de um Tribômetro para Estudos Relacionados a Materiais de Friç̧ão Veiculares, Dissertation, 84 pages. Federal University of Rio Grande do Sul, Brazil, 2008.

[10] H. P. Jost, Lubrication (Tribology) Education And Research, Jost Report, Department of Education and Science, HMSO, London, p.4., 1960.

[11] J. L. D. Ribeiro, C. S. Caten, Série Monográfica Qualidade: Projeto de Experimentos, Federal University of Rio Grande do Sul, Escola de Engenharia, Programa de Pós Graduação em Engenharia de Produção, Porto Alegre, RS, p. 43-54, 2011. 